\title{
Erratum to: Ethics of Information and Communication Technologies
}

\section{Erratum to:}

\section{A. Fabris, Ethics of Information and Communication Technologies, SpringerBriefs on Ethical and Legal Issues in Biomedicine and Technology, https://doi.org/10.1007/978-3-319-75511-3}

In the original version of the book, the line "Translation from the English language edition: Ethics of Information and Communication Technologies by Adriano Fabris, (c) Springer International Publishing AG 2018. All Rights Reserved. (C) Springer International Publishing AG 2018" was replaced with "Copyright (C) Springer International Publishing AG 2018. All Rights Reserved." in the Copyright page of the Frontmatter. 